\title{
Contribuição ao estudo anatômico do caule de Himatanthus sucuuba (Spruce ex Müll. Arg.) Woodson, Apocynaceae
}

\author{
C.R.R. Larrosa*, M.R. Duarte
}

Laboratório de Farmacognosia, Departamento de Farmácia, Universidade Federal do Paraná, Rua Pref. Lothário Meissner 3400, 80210-170, Curitiba, PR, Brasil

\begin{abstract}
RESUMO: Himatanthus sucuuba (Spruce ex Müll. Arg.) Woodson, Apocynaceae, denominada comumente de sucuuba ou janaguba, é uma espécie arbórea, latescente, da região amazônica, cujo tronco é ereto e a casca rugosa. As atividades antiinflamatória e analgésica e a baixa toxicidade foram estabelecidas em diferentes pesquisas. Com o objetivo de estabelecer caracteres anatômicos aplicáveis à identificação da planta e da droga vegetal, analisou-se o caule em estrutura secundária, que consiste da casca e da região caulinar mais interna. A primeira periderme é observada nas camadas subepidérmicas e o córtex constitui-se de numerosos laticíferos ramificados, idioblastos com cristais de oxalato de cálcio e células parenquimáticas contendo amiloplastos. Uma bainha esclerenquimática descontínua de fibras com paredes espessadas circunda o sistema vascular, cuja organização é bicolateral. As células do parênquima medular apresentam as mesmas características do córtex. Em níveis mais inferiores, a região cortical se reduz e numerosas fibras e células pétreas localizam-se no floema externo.
\end{abstract}

Unitermos: Himatanthus sucuuba, laticíferos, organização vascular bicolateral.

\begin{abstract}
Contribution to the anatomical study of the stem of Himatanthus sucuuba (Spruce ex Müll. Arg.) Woodson, Apocynaceae”. Himatanthus sucuuba (Spruce ex Müll. Arg.) Woodson, Apocynaceae, popularly known as sucuuba and janaguba, is a laticiferous woody species from the Amazonian region. The stem is upright and the bark is rugous. Different investigations have confirmed its anti-inflammatory and analgesic activities as well as low toxicity. Aiming to establish anatomical characters for the plant and drug identification, the stem in secondary growth, consisting of the bark and the most internal region, has been analysed. The first periderm is observed in the sub-epidermal layers and the cortex is composed of several branched laticifers, idioblasts containing calcium oxalate crystals and parenchymatic cells having amiloplasts. A noncontinuous sclerenchymatic sheath with thick cell-walled fibres encircles the vascular system, whose organization is bicollateral. The pith cells are similar to the cortex ones. On lower caulinar levels, the cortical region is reduced and numerous fibres and stone cells occur in the external phloem.
\end{abstract}

Keywords: Himatanthus sucuuba, laticifers, bicollateral vascular organization.

\section{INTRODUÇÃO}

O gênero Himatanthus foi descrito por Willdenow e é composto de espécies nativas da América do Sul, consistindo de árvores, arbustos ou subarbustos, latescentes. As espécies descritas estão dispersas na zona tropical desde a latitude $10^{\circ} \mathrm{N}$ até o Trópico de Capricórnio (Plumel, 1991).

Himatanthus sucuuba (Spruce ex Müll. Arg.) Woodson, da família Apocynaceae, ordem Gentianales e subclasse Asteridae (Cronquist, 1988), é uma árvore de grande porte, conhecida como sucuuba ou janaguba e nativa da região Amazônica, que fornece madeira para a construção civil e carpintaria (Corrêa, 1984). É uma espécie latescente, de tronco ereto e casca rugosa. Possui folhas glabras, coriáceas e de margens inteiras; as inflorescências estão dispostas em cimeiras terminais com poucas flores, grandes e brancas e os frutos são geminados em forma de duplo folículo contendo sementes aladas. $\mathrm{Na}$ medicina popular, o látex e as folhas são utilizados como antitumoral, antifúngico, antianêmico, vermífugo e no tratamento de gastrites e artrites (Fernades et al., 2000; Di Stasi; Hiruma-Lima, 2002). A infusão feita a partir da casca do caule tem sido usada para tratamento de tumores, furúnculos, edemas, artrites e ainda como vermífugo e laxativo (Fernandes et al., 2000).

Os compostos químicos mais isolados dessa planta são iridóides, encontrados no caule e no látex, como fulvoplumierina, plumericina (Perdue; Blomster, 1978), isoplumericina (Silva et al., 1998a; Wood et al., 2001), ácido confluêntico e ácido metilperlatólico (Endo et al., 1994). Com base em estudos farmacológicos, foram evidenciadas as atividades antiinflamatória e analgésica dos iridóides presentes na casca do caule e no látex (Silva 

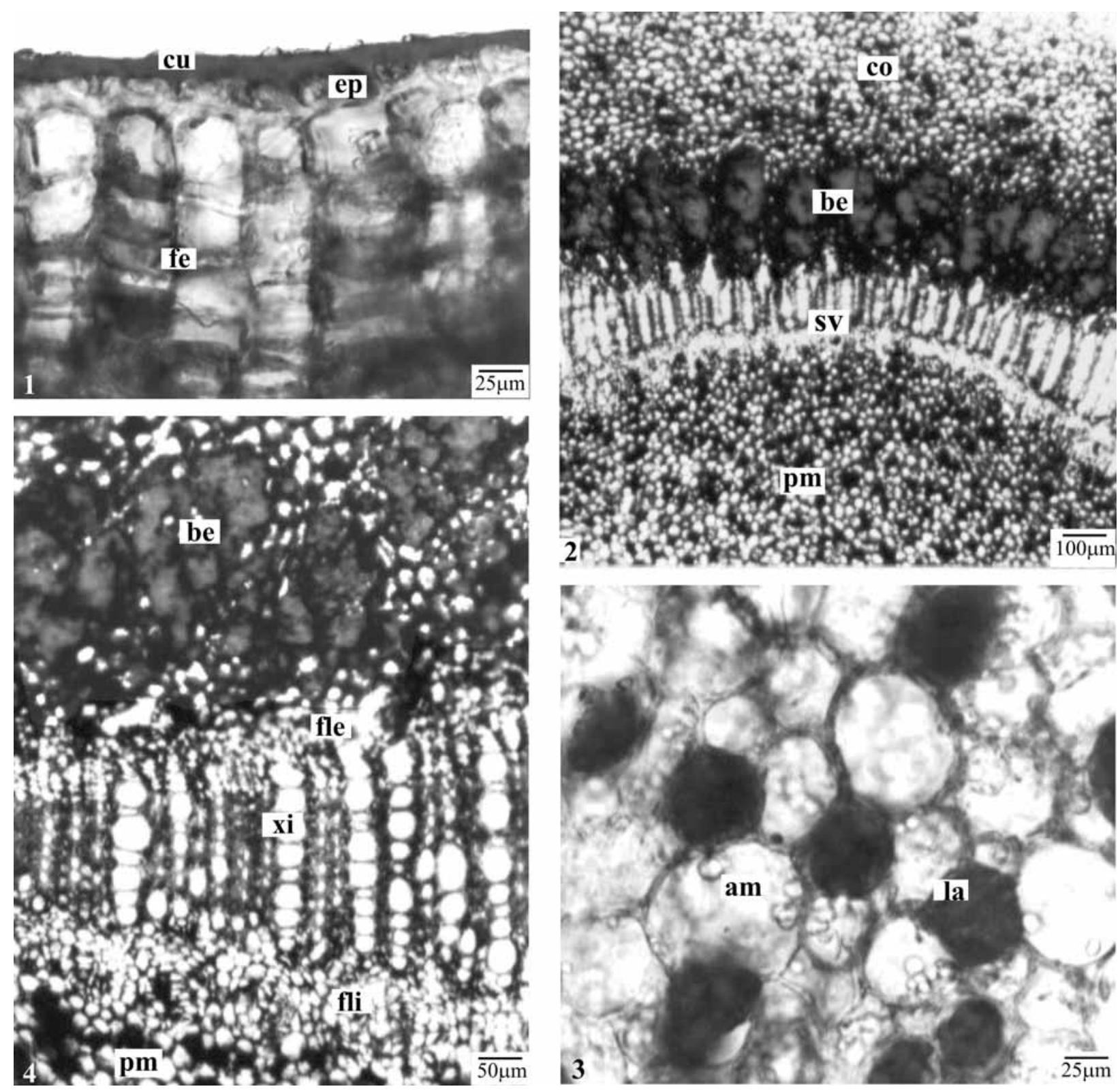

Figuras 1-4. Himatanthus sucuuba (Spruce ex Müll. Arg.) Woodson, Apocynaceae - caule em secção transversal: 1. instalação superficial do felogênio; 2. organização caulinar; 3. laticíferos em meio ao parênquima cortical contendo amiloplastos; 4. bainha esclerenquimática incompleta e arranjo vascular bicolateral. am - amiloplasto, be - bainha esclerenquimática, co - córtex, cu - cutícula, ep - epiderme, fe - felogênio, fle - floema externo, fli- floema interno, la - laticífero, pm - parênquima medular, sv - sistema vascular, xi - xilema.

et al., 1998b; Miranda et al., 2000), o efeito cicatrizante (Villegas et al., 1997) e uma baixa toxicidade reprodutiva e teratogênica em ratas, indicando que seu consumo é seguro na espécie humana no tratamento de gastrites e hemorróidas (Guerra; Peters, 1991).

Este trabalho objetivou estudar a anatomia do caule em estrutura secundária da espécie, o qual compreende a casca, região mais externa entre o sistema de revestimento e o câmbio vascular, e a região mais interna, que inclui xilema, floema interno e parênquima medular. Informaç̃os anatômicas referentes à casca têm aplicação na identificação da droga vegetal e os dados estruturais do xilema à medula são complementares na caracterização da planta medicinal.

\section{MATERIAL E MÉTODOS}

\section{Material vegetal}

O material vegetal foi coletado nas reservas do Instituto Nacional de Pesquisas Amazônicas (INPA), em Manaus - Amazonas, nas coordenadas $03^{\circ} 05^{\prime}$ 'S e $59^{\circ}$ 
59’W e em uma altitude de $80 \mathrm{~m}$, em julho de 2003. A amostra foi comparada pelo Prof. Dr. William Rodrigues do Departamento de Botânica da Universidade Federal do Paraná e coincide com exsicata registrada no herbário do INPA sob o número 80598.

\section{Metodologia}

Fragmentos caulinares obtidos a partir de $5 \mathrm{~cm}$ do ápice dos ramos foram fixados em FAA 70 (Johansen, 1940), conservados em etanol a 70\% (Berlyn; Miksche, 1976) e seccionados, à mão livre, nos sentidos transversal e longitudinal. Os cortes foram submetidos à coloração com azul de toluidina (O’Brien; Feder; McCully, 1965) ou com azul de astra e fucsina básica (Roeser, 1962). Os resultados foram registrados por meio de fotomicrografias em microscópio fotônico Olympus BX 40, acoplado à unidade de controle PM-20.

Foram realizados testes microquímicos, utilizando-se floroglucina clorídrica para verificação de lignina (Foster, 1949), Sudam III para substâncias lipofílicas (Sass, 1951), cloreto férrico para compostos fenólicos (Johansen, 1940), lugol para amido (Berlyn; Miksche, 1976) e ácido sulfúrico para cristais de oxalato de cálcio(Oliveira; Akisue, 1989).

\section{RESULTADOS}
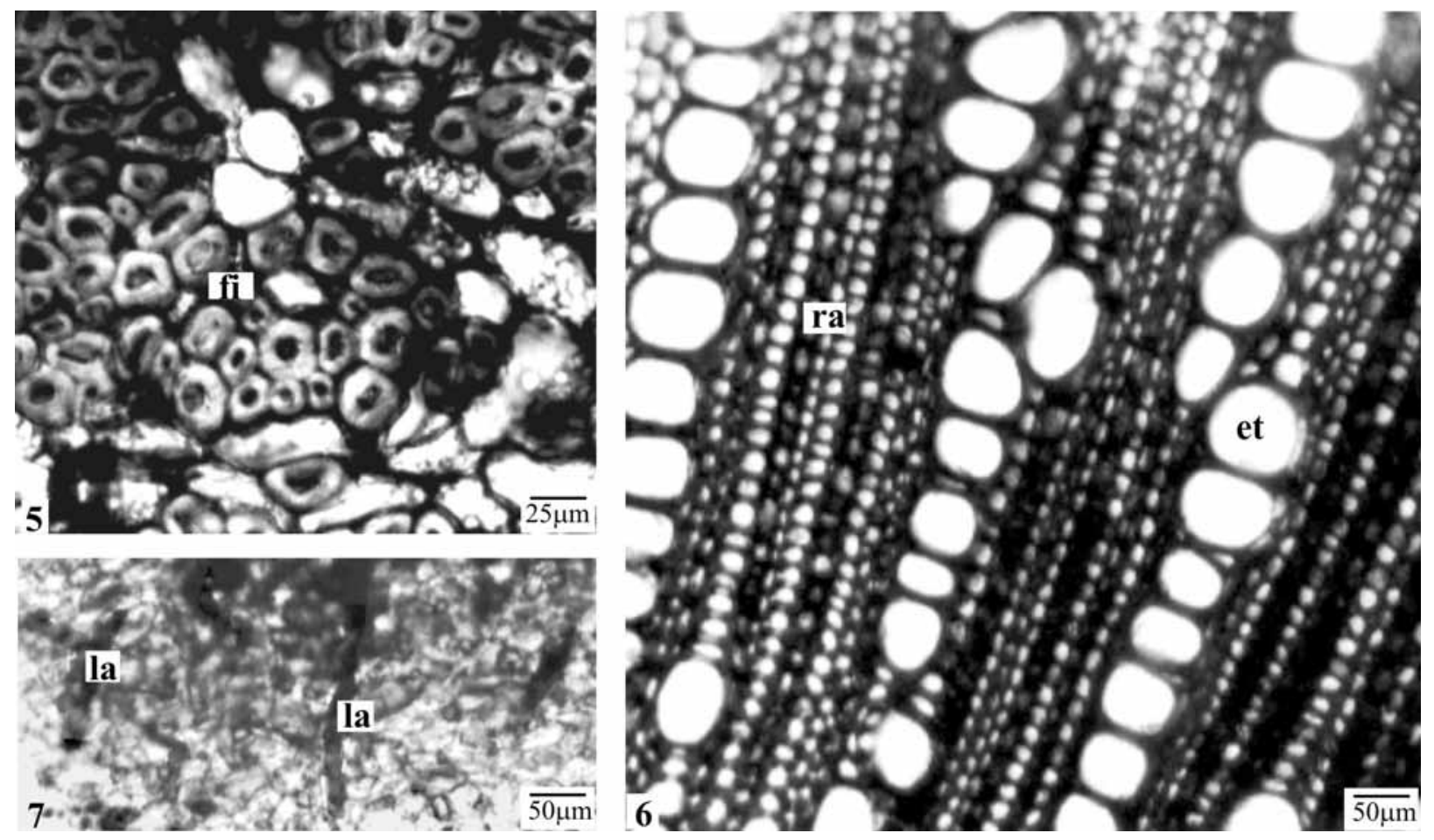

O caule, nas proximidades do ápice, em estrutura secundária incipiente, apresenta a epiderme como sistema de revestimento. Esta é composta por uma única camada de células, revestida por uma cutícula espessada e estriada. Em vista frontal, as paredes anticlinais das células epidérmicas revelam formato poligonal. Em decorrência do aumento de circunferência do caule, a epiderme é substituída pela periderme, instalandose o primeiro felogênio nas camadas subepidérmicas (Figura 1). Este forma súber em direção à periferia, que consiste de numerosos estratos de células tabulares, com paredes suberizadas e levemente lignificadas. No córtex ocorrem células parenquimáticas de paredes delgadas, aproximadamente isodiamétricas, contendo grande quantidade de amiloplastos (Figuras 2 e 3). Observamse idioblastos contendo cristais de oxalato de cálcio na forma de drusas e predominantemente de prismas e também numerosos laticíferos (Figura 3), cujo conteúdo reage positivamente à pesquisa de substâncias lipofílicas e de compostos fenólicos. Os laticíferos são ramificados (Figura 7), comparativamente maiores do que as células que os ladeiam e possuem citoplasma denso. Existe uma bainha esclerenquimática descontínua (Figuras 4 e 5) formada de vários estratos de fibras, de paredes evidentemente espessadas e lúmen reduzido, envolvendo o sistema vascular. Raras fibras apresentam paredes lignificadas, sendo que a impregnação com lignina, quando ocorre, é apenas nas camadas mais externas

Figuras 5-7. Himatanthus sucuuba (Spruce ex Müll. Arg.) Woodson, Apocynaceae - caule em secção transversal: 5. detalhe da bainha esclerenquimática, constituída de fibras; 6. disposição dos elementos traqueais e raios parenquimáticos lignificados; 7. laticíferos ramificados. et - elemento traqueal, fi - fibra, la - laticífero, ra - raio parenquimático. 
das paredes. O sistema vascular apresenta arranjo bicolateral (Figura 4), onde os floemas externo e interno constituem-se de elementos crivados em meio a células parenquimáticas especializadas e não-especializadas e laticíferos ramificados. O primeiro dispõe-se como um anel contínuo e o segundo, em cordões lado a lado. O floema externo apresenta fibras lignificadas e o xilema é totalmente lignificado, formado por elementos traqueais dispostos em fileiras, separadas por células parenquimáticas contendo amiloplastos. Em níveis mais inferiores do caule, a região cortical é proporcionalmente reduzida, o floema externo apresenta numerosas fibras e células pétreas e, no xilema, os elementos traqueais se dispõem em pequenos grupos enfileirados ou isolados em meio à grande quantidade de células lignificadas, sendo distinguíveis raios estreitos, compostos de uma ou duas fileiras, contendo amiloplastos (Figura 6). O parênquima medular (Figura 2) consiste de células parenquimáticas aproximadamente isodiamétricas, de paredes delgadas e que podem conter compostos fenólicos. Amiloplastos, numerosos laticíferos ramificados, bem como idioblastos com drusas e, na maioria, prismas de oxalato de cálcio estão presentes.

\section{DISCUSSÃO}

As Apocynaceae caracterizam-se pela origem superficial do felogênio no caule (Metcalfe; Chalk, 1950; Cronquist, 1981), ocorrendo dessa maneira na espécie em questão, onde esse meristema lateral se instala nas camadas subepidérmicas. Na família, a periderme consiste tanto de células de paredes finas, quanto de paredes esclerificadas e que podem conter cristais (Metcalfe; Chalk, 1950). Em Himatanthus sucuuba (Spruce ex Müll. Arg.) Woodson, a periderme é pouco esclerificada e não possui cristais, conferindo parcialmente com Mandevilla illustris (Vell.) Woodson, M. velutina (Mart. ex Stadelm) Woodson (Appezzato da Glória, 1993) e Aspidosperma olivaceum Muell. Arg. (Kulkarni et al., 1973), para as quais não foi mencionada impregnação de lignina na periderme.

Cristais de oxalato de cálcio são comuns na maioria dos caules de Apocynaceae, segundo Metcalfe e Chalk (1950) e Cronquist (1981), e são encontrados no córtex e no parênquima medular da espécie analisada. De um modo geral, os cristais são úteis como suporte estrutural, proteção contra herbívoros e manutenção do balanço iônico, pelo armazenamento de oxalato e cálcio nos idioblastos (Franceschi; Horner Jr., 1980).

No córtex e no parênquima medular são evidenciados também amiloplastos, assim como em Catharanthus roseus (L.) G. Don (Pacheco, 1980). O amido contido nesses amiloplastos tem função de reserva e geralmente ocorre no córtex, no sistema vascular e no parênquima medular (Esau, 1974).

Quase invariavelmente, na família, ocorrem fibras não lignificadas, isoladas ou em grupos no periciclo (Metcalfe; Chalk, 1950; Cronquist, 1981).
Coincidentemente na espécie em estudo, essas fibras são observadas envolvendo o sistema vascular. Também foram relatadas em C. roseus (Pacheco, 1980), A. olivaceum (Kulkarni et al., 1973) e M. illustris e $M$. velutina (Appezzato da Glória, 1993).

Floema interno foi constatado em exemplares de caules examinados em espécies de Apocynaceae (Metcalfe; Chalk, 1950), podendo apresentar-se como um anel contínuo ou cordões isolados (Metcalfe; Chalk, 1950; Cronquist, 1981), sendo esta a organização presente na espécie analisada. O floema interno é muito eficiente na condução e, portanto, de grande vantagem para as plantas do deserto, que estão sujeitas a períodos de fotossíntese curtos mais intensos, segundo Fahn (1990) e Appezzato da Glória (1993). No entanto, embora esteja presente em $H$. sucuuba, esse caráter xeromorfo não condiz com a origem da mesma, que é proveniente da região tropical amazônica. Para Esau (1974), à parte a deficiência hídrica, outros fatores ambientais podem induzir um grau de xeromorfia mais marcante, como a insuficiência de nutrientes, o frio e a luz intensos. Plantas que se desenvolvem sob maior intensidade luminosa mostram um grau de xeromorfia maior que aquelas protegidas da luz.

O sistema vascular é tipicamente bicolateral em Apocynaceae, em concordância com o evidenciado em $H$. sucuuba. Comparativamente, considerando taxa superiores, feixes bicolaterais são encontrados também em Convolvulaceae, Solanaceae e Asteraceae, pertencentes a ordens diversas da subclasse Asteridae (Esau, 1974; Mauseth, 1988; Fahn, 1990).

As características anatômicas de ocorrência universal na família são floema interno e laticíferos. Estes são encontrados no córtex, no floema e no parênquima medular em $H$. sucuuba. Metcalfe e Chalk (1950) relataram que laticíferos estão sempre presentes no caule, situados no córtex, periciclo, floema, parênquima medular e algumas vezes nos raios medulares.

Considerados estruturas especializadas, os laticíferos produzem látex, que é uma suspensão ou emulsão de pequenas partículas em um líquido. Consistem de uma única célula longa ou de uma série de células (Fahn, 1990), cuja parede celular pode ser irregularmente espessada, em razão da plasticidade da mesma (Mahlberg, 1993). Apresenta-se inteiramente primária, contendo celulose, grande quantidade de substâncias pécticas e hemicelulose (Murugan; Inamdar, 1987; Fahn, 1990). A título de comparação, os laticíferos observados em folha de Plumeria alba L. possuem tamanho maior que as células circunvizinhas, núcleo proeminente, citoplasma denso, formato poligonal ou circular em secção transversal, sem grãos de amido no seu interior (Murugan, Inamdar, 1987), de modo similar à espécie em estudo.

\section{CONCLUSÃO}

Como caracteres anatômicos relevantes à 
identificação da casca, pode-se destacar a presença de laticíferos ramificados, prismas e drusas de oxalato de cálcio, fibras e células pétreas no floema externo. Adicionalmente, a observação de xilema totalmente lignificado com elementos traqueais enfileirados ou em grupos e floema interno disposto em cordões isolados complementam os caracteres estruturais do caule, os quais contribuem para a identificação da planta medicinal.

\section{AGRADECIMENTOS}

À Coordenação de Aperfeiçoamento de Pessoal de Nível Superior (CAPES) pela bolsa concedida à pósgraduanda C.R.R. Larrosa.

\section{REFERÊNCIAS}

Appezzato da Glória B 1993. Caracteres anatômicos e ultraestruturais dos órgãos vegetativos de Mandevilla illustris (Vell.) Woodson e de M. velutina (Mart. ex Stadelm.) Woodson - Apocynaceae. São Paulo, 122 p. Tese de Doutorado - Instituto de Biociências, Universidade de São Paulo.

Berlyn GP, Miksche JP 1976. Botanical microtechnique and cytochemistry. Ames: Iowa State University.

Corrêa MP 1984. Dicionário das plantas úteis do Brasil e das exóticas cultivadas. Rio de Janeiro: Imprensa Nacional. v. 6.

Cronquist A 1981. An integrated system of classification of flowering plants. New York: Columbia University Press.

Cronquist A 1988. The evolution and classification of flowering plants. 2.ed. New York: The New York Botanical Garden.

Di Stasi LC, Hiruma-Lima CA 2002. Plantas medicinais na Amazônia e na Mata Atlântica. 2.ed. São Paulo: UNESP.

Endo Y, Hayashi H, Sato T, Maruno M, Ohta T, Nozoe S 1994. Confluentic acid and 2'-O-methylperlatolic acid, monoamine oxidase B inhibitors in a Brazilian plant, Himatanthus sucuuba. Chem Pharm Bull 42: 11981201.

Esau K 1974. Anatomia das plantas com sementes. São Paulo: Edgard Blücher.

Fahn A 1990. Plant anatomy. $4^{\mathrm{a}}$ ed. Oxford: Pergamon Press.

Fernandes MZLCM, Fernandes RM, Sousa MCBB, Lopes JB 2000. Determinação da toxicidade aguda da Himatanthus sucuuba (Spruce) Woodson (Apocynaceae) em camundongos. Rev Bras Farm 81: $98-100$

Foster AS 1949. Practical plant anatomy. 2. ed. Princeton: D. Van Nostrand.

Franceschi VR, Horner Jr. HT 1980. Calcium oxalate crystals in plants. Bot Rev 46: 361-427.

Guerra MO, Peters VM 1991. Screening for reproductive toxicity in rats for a decoction of Himatanthus sucuuba stem bark. J Ethnopharmacol 34: 195-199.

Johansen DA 1940. Plant microtechnique. New York: McGraw Hill Book.

Kulkarni JD, Ramstad E, Rowson JM, Trease GE 1973. The pharmacognosy of the Aspidosperma barks of Brasil.
Planta Med 23: 23-34.

Mahlberg PG 1993. Laticifers: an historical perspective. Bot Rev 59: 1-23.

Mauseth JD 1988. Plant anatomy. Menlo Park: Benjamin/ Cummings.

Metcalfe CR, Chalk L 1950. Anatomy of the dicotyledons. Oxford: Clarendon Press. v. 2.

Miranda ALP, Silva JRA, Rezende CM, Neves JS, Parrini SC, Pinheiro MLB, Cordeiro MC, Tamborini E, Pinto AC 2000. Anti-inflammatory and analgesic activities of the latex containing triterpenes from Himatanthus sucuuba. Planta Med 66: 284-286.

Murugan V, Inamdar JA 1987. Organographic distribution, structure and ontogeny of laticifers in Plumeria alba Linn. Proc Indian Acad Sci (Plant Sci) 97: 25-31.

O’Brien TP, Feder N, McCully ME 1965. Polychromatic staining of plant cell walls by toluidine blue O. Protoplasma 59: 368-373.

Oliveira F, Akisue G 1989. Fundamentos de farmacobotânica. São Paulo: Livraria Atheneu.

Pacheco JM 1980. Contribuição ao estudo anatômico da espécie Catharanthus roseus (L.) G. Don var. roseus (Apocynaceae). Rodriguésia 32: 39-54.

Perdue GP, Blomster RN 1978. South-American plants 3. Isolation of fulvoplumierin from Himatanthus sucuuba (M. Arg.) Woodson (Apocynaceae). J Pharm Sci 67: 1322-1323.

Plumel MM 1991. Le genre Himatanthus (Apocynaceae) révision taxonomique. Bradea 5: 1-118.

Roeser KR 1962. Die Nadel der Schwarzkiefer-Massenprodukt und Kunstwerk der Natur. Mikrokosmos 61: 33-36.

Sass JE 1951. Botanical microtechnique. 2. ed. Ames: Iowa State College.

Silva JRA, Rezende CM, Pinto AC, Pinheiro MLB, Cordeiro MC, Tamborini E, Young CM, Bolzani VS 1998(a). Ésteres triterpênicos de Himatanthus sucuuba (Spruce) Woodson. Quim Nova 21: 702-704.

Silva JRA, Pessoni RAB, Vieira CCJ, Rezende CM, Miranda ALP, Pinto AC 1998(b). Composição e atividade antinflamatória e analgésica do látex de Himatanthus sucuuba (Spruce) Woodson (Apocynaceae). XV Simpósio de Plantas Medicinais do Brasil. Águas de Lindóia, Brasil.

Villegas LF, Fernández ID, Maldonado $H$, Torres $R$, Zavaleta A, Vaisberg AJ, Hammond GB 1997. Evaluation of the wound-healing activity of selected traditional medicinal plants from Peru. J Ethnopharmacol 55: 193-200.

Wood CA, Lee K, Vaisberg AJ, Kingston DGI, Neto CC, Hammond GB 2001. A bioactive spirolactone iridoid and triterpenoids from Himatanthus sucuuba. Chem Pharm Bull 49: 1477-1478. 